\title{
La tecnología en el desarrollo de la sociedad. Un debate necesario
}

En el complejo universo actual, donde se debaten diversas teorías científicas, se establecen paradigmas direccionados del conocimiento, y se trabaja desde un aparataje tecnológico, que de manera abrumadora construye la existencia de los seres humanos, el hecho de considerar en el ámbito del desarrollo de la sociedad es algo que inevitablemente ocurre día a día. En este contexto el asumir los retos y desafíos que dicha tecnología, le coloca a la formación de los seres humanos, se convierte en una oportunidad ineludible para lograr crecimientos a nivel del pensamiento teórico y de la práctica institucional educativa, en cuanto a la introducción de los avances de la ciencia y la tecnología en función del desarrollo pleno del hombre.

La condición humana, heredera de diversa tradiciones, escuelas y prácticas culturales, hoy ha sido invadida y moldeada por la llamada "Era de la información" y por la "Sociedad del conocimiento", se ha visto afectada de manera significativa con el surgimiento de los entornos hipermediales y comunicativos, cada vez más supeditados a la comunicación tecnológica, ello ha provocado movimientos educativos y sociales que con fuerza telúrica, han sacudido los cimientos de la pedagogía y la escuela. He aquí un impacto verdaderamente trascendente de los logros científicos del siglo $X X$ y de estas primeras décadas del siglo $X X I$, la distancia temporal que existía entre el descubrimiento científico y su aplicación tecnológica, se ha reducido de manera significativa. Esta arista enriquecedora de la actividad formativa del hombre como especie, da un espaldarazo importante a las búsquedas científicas, sus teorías de la complejidad y la generación de tecnologías limpias que potencien los espacios de realización humanas.

En la vida diaria, el impacto de la tecnología es tal, que a ninguno de nosotros se nos ocurriría adjurar de la misma, el desarrollo vertiginoso de la industria automotriz, de la construcción, y las industrias culturales, ha estado amparado en estas. Hoy vemos a nuestros seres queridos casi de modo presencial, por medio de diversos dispositivos telemáticos, la escuela se ha salvado en el contexto de la pandemia, por la gran 
cantidad de plataformas virtuales de aprendizaje, se reordenan los procesos productivos y comerciales al amparo de las facilidades del teletrabajo, la telemedicina, etc.

Por estas razones antes tratadas, es real hoy más que nunca el desafío de asumir a las tecnologías como oportunidad de crecimiento y empoderamiento de los seres humanos y como reafirmación de la importancia de las ciencias técnicas en la construcción social del conocimiento, el desarrollo de proyectos de vida y la generación de nuevos conocimientos que contribuyan a alcanzar sociedades más justas, participativas y sustentables. Algunos temerán de esta vertiginosidad tecnológica, otros se adscriben a la misma como devotos, así y de muchas otras formas la sociedad asimila su existencia, pero siempre bajo la certeza de que en la ciencia y en la tecnología, están dos grandes aliados del desarrollo humano y de la posibilidad colectiva de crear sociedades verdaderamente postmodernas e inclusivas.

\section{Ing. Gilma Rivera Segura}

Universidad Regional Autónoma de Los Andes, Quevedo

$$
\text { Ecuador }
$$

https://orcid.org/0000-0003-1312-5446 